\title{
Pengaruh Kualitas Produk layanan dan Citra Merek (Brand Image) Terhadap Loyalitas Melalui Kepuasan Sebagai Variabel Intervening Pada Pengguna Simcard IM3 (Studi Pada Mahasiswa Jurusan Administrasi Bisnis FISIP Undip)
}

\author{
Widayanto $^{1, *}$ \\ ${ }^{1}$ Departemen Administrasi Bisnis, Fakultas Ilmu Sosial dan Ilmu Politik, Universitas Diponegoro, Indonesia \\ *Email: widafisip.undip@,gmail.com
}

\begin{abstract}
The fast development of information technology has been giving positive impact on its users. This is very enough perceived in the sector of communication. The distance-separated people can still communicate without experiencing obstacles and difficulties. The easiness in communicating is perceivedly more and more increasing with the number of telecomunnication provider. Each provider to other providers, has been competing for consumers' satisfication. For this goal, the strategy done by that provider is to give good quality of service dan brand image. This type of research is explanatory research, with a population of 100 students from the Department of Business Administration of FISIP, Undip, which are registering and using IM3 card. Sampling on this study uses a non-probability sample which is known as purposive sampling method. The data was collected through questionnaires. The method of analyzing data is Partial Least Square (PLS) analysis, Mediation / Intervening Testing using Variance Accounted For (VAF) and Fit Model Indicators (Model of Indices) using WarpPLS 6. Based on the results of the analysis using WarpPLS 6.0, it can be explained that the results of test of the direct influence on this research model show positive and significant influence. The results of the test of indirect effects on the model also show positive and significant influence. The satisfaction variable as mediation in the model is Partial Mediation. Researcher suggest that the signal of IM3 can be expanded more to be able to expand the range of user communication. In addition, IM3 providers should be able to design IM3 card physical products easier to use.
\end{abstract}

Abstraksi Perkembangan teknologi informasi yang semakin pesat, memberikan dampak positif bagi penggunanya. Hal tersebut sangat terasa pada bidang telekomunikasi. Orang-orang yang terpisahkan oleh jarak, tetap dapat berkomunikasi tanpa mengalami kendala dan kesulitan. Kemudahan berkomunikasi tersebut, semakin dirasakan dengan semakin pesatnya perkembangan jumlah penyedia jasa (provider) sarana telekomunikasi. Masing-masing provider saling berlomba untuk dapat memberikan kepuasan kepada konsumen atas layanan yang diberikan, dengan harapan konsumen akan loyal dan tidak pindah ke "lain hati". Agar tujuan tersebut dapat diraih, strategi yang digarap provider diantaranya adalah kualitas produk layanan yang baik dan citra merek. Tipe penelitian ini adalah explanatory research, dengan populasi Mahasiswa Jurusan Administrasi Bisnis Fisip Undip yang menggunakan kartu provider IM3 sebanyak 100 responden. Pengambilan sampel pada penelitian ini menggunakan non-probability sampling, yakni dengan metode purposive sampling. Data dikumpulkan melalui kuesioner. Metode analisis data yang digunakan menggunakan analisis Partial Least Square (PLS), Pengujian Mediasi/Intervening dengan menggunakan Variance Accounted For (VAF) dan Indikator Fit Model (Model of Indices) dengan menggunakan WarpPLS 6.0. Berdasarkan hasil analisis perhitungan WarpPLS 6.0 dapat dijelaskan bahwa hasil uji pengaruh langsung pada model penelitian ini menunjukkan hasil pengaruh yang positif dan signifikan. Hasil uji pengaruh tidak langsung pada model juga menunjukkan hasil pengaruh positif dan signifikan. Variabel kepuasan sebagai pemediasi dalam model adalah Partial Mediation. Peneliti menyarankan agar jangkauan signal IM3 dapat diperluas lagi. Agar lebih dapat memperluas jangkauan komunikasi penggunanya. Selain itu, hendaknya provider IM3 dapat merancang produk fisik kartu IM3 lebih mudah penggunaannya.

Keywords: Products Quality; Brand Image; Satisfication and Loyality

\section{Pendahuluan}

Perkembangan teknologi informasi dan sistem informasi dewasa ini yang semakin pesat, memberikan dampak positif bagi penggunanya. Kondisi tersebut dapat dilihat dalam bidang telekomunikasi. Orang-orang yang terpisahkan oleh jarak, tetap dapat 
berkomunikasi tanpa mengalami kendala dan kesulitan. Kemudahan berkomunikasi tersebut, semakin dirasakan dengan semakin pesatnya perkembangan jumlah penyedia jasa (provider) sarana telekomunikasi. Dalam upaya mendapatkan pelanggan yang sebanyak-banyaknya, para penyedia jasa tesebut berlomba-lomba menyusun strategi untuk memanjakan konsumennya dengan berbagai layanan yang diberikan. Tentu saja penyedia jasa yang dapat memberikan pelayanan lebih dibanding pesaingnya, maka penyedia jasa tersebut yang mendapatkan tempat di hati konsumennya. Dengan kondisi semakin banyaknya penyedia jasa tersebut, maka tingkat persaingan yang dirasakan pun semakin tinggi.

Salah satu strategi untuk memenangkan persaingan yang diterapkan oleh penyedia jasa adalah produk dengan kualitas yang baik. Melalui kualitas produk yang baik yang dapat memenuhi keinginan konsumen, diikuti dengan fitur yang disediakan serta produk tersebut memiliki keunggulan dibanding pesaingnya, tentu saja pilihan konsumen akan jatuh pada produk yang memiliki kualitas yang baik tersebut.

Maka, pengalaman yang baik tentang penggunaan yang dirasakan oleh konsumen dalam pemakaian produk merupakan salah satu hal yang ingin dicapai oleh penyedia jasa. Karena melalui pengalaman tersebut, akan membentuk kesan yang baik di benak konsumen, serta lambat laun hal tersebut akan membentuk citra positif terhadap suatu merek yang disebut sebagai citra merek atau brand image. Membahas tentang merek, Frontier Consulting Group, melakukan survey dengan menggunakan metodologi yang dapat dipertanggungjawabkan kebenarannya untuk memberikan Top Brand Award untuk simcard prabayar pada Tabel 1.

Jika dilihat pada Tabel 1, IM3 menduduki posisi ke-2 dalam urutan top brand indeks. Posisi tersebut mengindikasikan bahwa dari sisi merek yang dikenal oleh konsumen pengguna telepon seluler, IM3 berada pada posisi urutan ke-2. Upaya untuk mendapatkan posisi pertama top brand, IM3 masih harus berjuang keras bersaing dengan
Simpati yang paling banyak mendapatkan kedudukan di "hati" konsumen.

Tabel 1. Simcard Prabayar

\begin{tabular}{lcl}
\hline \multicolumn{1}{c}{ Merek } & TBI & TOP \\
\hline Simpati & $35,5 \%$ & TOP \\
IM3 & $15,4 \%$ & TOP \\
XL Prabayar & $14,8 \%$ & TOP \\
Tri '3' & $11,3 \%$ & \\
Kartu AS & $10,4 \%$ & \\
Axis & $5,1 \%$ & \\
\hline
\end{tabular}

Sumber: $\quad$ http://www.topbrand-award.com, 2016.

Mahasiswa sebagai salah satu bagian dari segmen yang dibidik oleh provider penyedia jasa telekomunikasi merupakan salah satu segmen pemakai produk yang potensial. Hal tersebut tidak dapat dipungkiri karena untuk mendukung aktifitas kegiatan belajar, menurut pengakuan mahasiswa merasa sangat diuntungkan dengan keberadaan sarana komunikasi berupa telepon seluler tersebut. Dan mengapa IM3 yang dipilih sebagai obyek dalam penelitian ini, meskipun hasil survey Frontier Consulting Group Simpati menduduki peringkat 'pertama' top brand indeks, namun karena berdasarkan survey awal yang dilakukan terhadap 150 mahasiswa jurusan Administrasi Bisnis FISIP undip yang memiliki dan menggunakan telepon seluler dalam mendukung aktivitasnya. Hasil survey tersebut menunjukkan bahwa mahasiswa yang menggunakan IM3 menduduki peringkat pertama sebesar $62,7 \%$. Hasil survey awal tersebut dapat dipaparkan dalam bentuk Gambar 1.

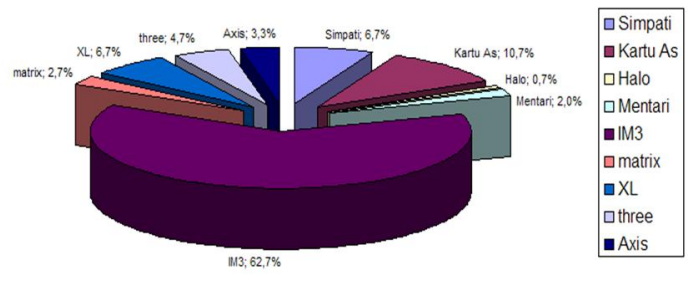

Gambar 1. Mahasiswa Jurusan Administrasi Bisnis Pengguna Kartu Telepon Seluler

Sumber: Data survey awal penelitian (2016) 
Berpijak dari fenomena tersebut di atas, maka peneliti tertarik untuk melakukan penelitian dengan judul Pengaruh Kualitas Produk dan Citra Merek (Brand Image) Terhadap Loyalitas Melalui Kepuasan Sebagai Variabel Intervening Pada Pengguna Simcard IM3 (Studi Pada Mahasiswa Jurusan Administrasi Bisnis).

\section{Kajian Teori}

\section{Kualitas Produk}

Kotler (2002) kualitas produk adalah keseluruhan ciri serta dari suatu produk atau pelayanan pada kemampuan untuk memuaskan kebutuhan yang dinyatakan atau tersirat.

\section{Citra Merek}

Menurut Kotler dan Keller (2009) brand image adalah persepsi dan keyakinan yang dipegang oleh konsumen, seperti yang dicerminkan asosiasi yang tertanam dalam ingatan konsumen.

\section{Kepuasan}

Menurut Kotler (2004) tingkat perasaan senang atau kecewa seseorang yang muncul setelah membandingkan antara persepsi/ kesannya terhadap kinerja (hasil) suatu produk dan harapan-harapannya.

\section{Loyalitas}

Menurut Nugroho (2005) adalah suatu ukuran kesetiaan dari pelanggan dalam menggunakan suatu merek produk atau merek jasa pada kurun waktu tertentu pada situasi dimana banyak pilihan produk ataupun jasa yang dapat memenuhi kebutuhannya dan pelanggan memiliki kemampuan mendapatkannya.

\section{Metode}

Untuk menguji hipotesis yang akan diajukan, digunakan teknik analisis PLS
(Partial Least Square) yang dioperasikan melalui program WarpPLS 6.0. Hipotesis merupakan jawaban sementara terhadap rumusan masalah penelitian, jawaban yang diberikan baru didasarkan pada fakta-fakta empiris yang diperoleh melalui pengumpulan data. Jadi hipotesis dinyatakan dalam jawaban teoritis terhadap rumusan masalah penelitian.

\section{Jenis Data}

Jenis data yang digunakan dalam penelitian ini ada 2, yaitu: Data Kualitatif dan Data Kuantitatif. Data kualitatif adalah data yang tidak berbentuk angka. Penelitian ini menggunakan data yang bersifat kualitatif seperti hasil dialog dengan responden, informasi pada website mengenai teknologi informasi. Data kuantitatif adalah data yang berbentuk angka. Penelitian ini juga menggunakan data kuantitatif seperti: kuantifikasi jawaban pada kuisioner.

\section{Sumber Data}

Data yang digunakan dalam penelitian ini adalah data primer dan data sekunder. Data Primer adalah materi informasi yang diperoleh peneliti secara langsung ditempat penelitian. Data primer didapatkan dengan menggunakan instrumen kuesioner. Data sekunder adalah data yang diperoleh secara tidak langsung atau melalui pihak lain, atau laporan historis yang telah disusun dalam arsip yang dipublikasikan atau tidak dalam bentuk sudah jadi, sudah dikumpulkan dan diolah oleh pihak lain.

\section{Skala Pengukuran}

Penelitian ini menggunakan rating scale. Rating scale digunakan untuk menguantifikasi kesan dengan cara responden memberikan penilaian pada angka yang telah disediakan, sebagai berikut:

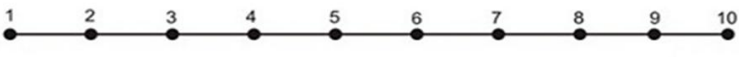




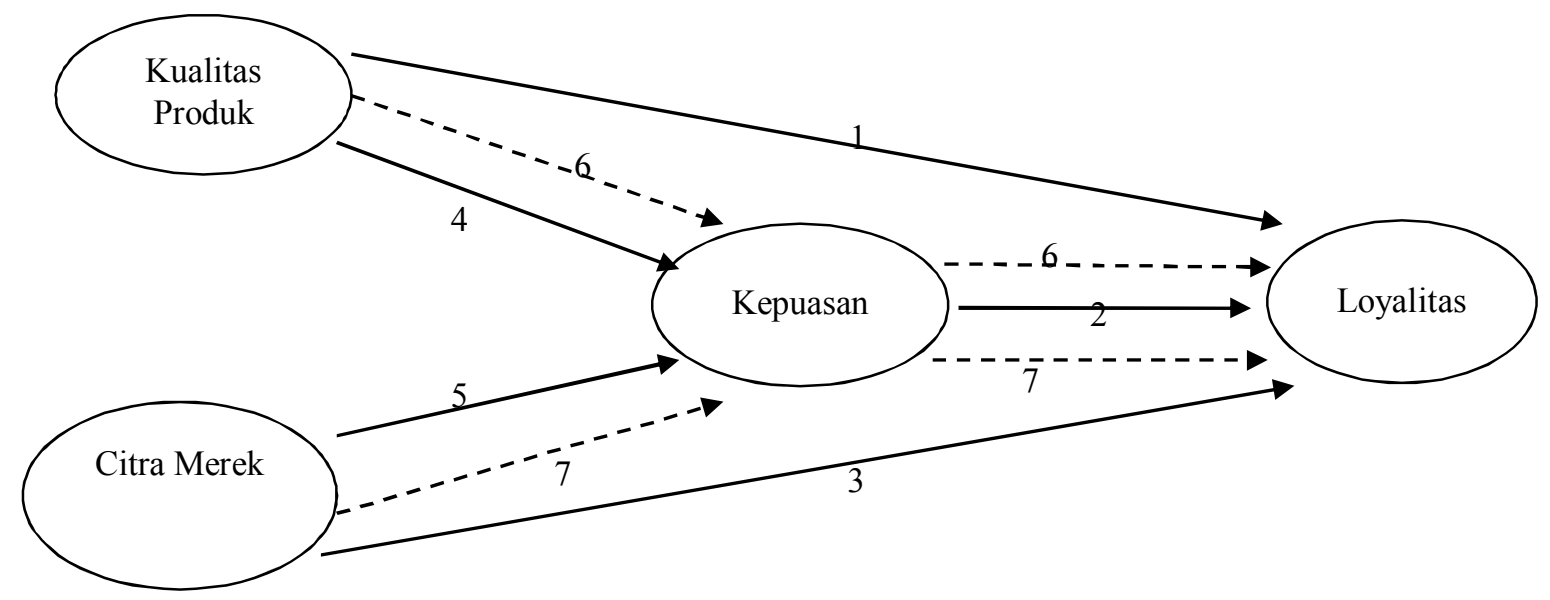

\section{Gambar 2. Model Hipotesis} ini:

Hipotesis yang diajukan dalam penelitian

Hipotesis 1: Diduga ada pengaruh Kualitas Produk terhadap Kepuasan pada pengguna simcard IM3.

Hipotesis 2: Diduga ada pengaruh Citra Merek terhadap Kepuasan pada pengguna simcard IM3.

Hipotesis 3: Diduga ada pengaruh Kualitas Produk terhadap Loyalitas pada pengguna simcard IM3.

Hipotesis 4: Diduga ada pengaruh Citra Merek terhadap Loyalitas pada pengguna simcard IM3.

Hipotesis 5: Diduga ada pengaruh Kepuasan terhadap Loyalitas pada pengguna simcard IM3.

Hipotesis 6: Diduga ada pengaruh Kualitas Produk terhadap Loyalitas melalui kepuasan pada pengguna simcard IM3.

Hipotesis 7: Diduga ada pengaruh Citra Merek terhadap Loyalitas melalui kepuasan pada pengguna simcard IM3.

\section{Hasil dan Pembahasan}

Penelitian ini bertujuan untuk mengetahui model penelitian dalam penelitian ini dapat diterima sesuai dengan goodness of fit atau tidak. Prosedur dalam pengujian model tersebut harus memenuhi beberapa persyaratan sebelum memutuskan apakah model penelitian ini diterima. Hasil pengujian model ini diperoleh dari kuesioner yang telah diisi oleh 100 responden kemudian diolah dengan uji statistika dan dianalisis.

Pada tahap pertama yaitu hasil uji pengaruh langsung dalam model adalah terbukti berpengaruh dan signifikan pada variabel Kualitas Produk dan Kepuasan sebesar 0.300 dengan signifikansi nilai $\mathrm{p}<0.001$. Hasil uji pengaruh langsung antara variabel Citra Merek berpengaruh positif langsung terhadap Kepuasan sebesar 0.509 dengan signifikasi nilai $\mathrm{p}<0.001$. Kualitas Produk berpengaruh positif langsung terhadap Loyalitas sebesar 0.379 dengan signifikasi nilai $\mathrm{p}<0.001$. Citra Merek berpengaruh positif langsung terhadap Loyalitas sebesar 0.210 dan signifikan dengan nilai $\mathrm{p}=0.014$. Kepuasan berpengaruh positif langsung terhadap Loyalitas sebesar 0.233 dan signifikan dengan nilai $\mathrm{p}=0.007$. Pengaruh langsung yang paling kuat adalah variabel Citra Merek terhadap Kepuasan. 


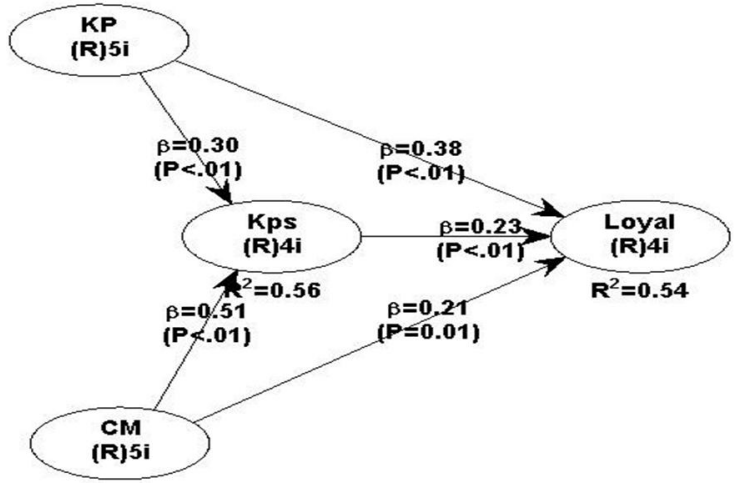

Gambar 3. Diagram Path Analysis Model

Sumber: Data Primer, diolah (2018)

Tabel 2. Direct effect pada Output path coefficient

\begin{tabular}{lcccc}
\hline & KP & CM & Kps & Loyal \\
\hline KP & & & & \\
CM & & & & \\
Kps & 0.300 & 0.509 & & \\
Loyal & 0.379 & 0.210 & 0.233 & \\
\hline
\end{tabular}

Tabel 3. P values

\begin{tabular}{lcccc}
\hline & KP & CM & Kps & Loyal \\
\hline KP & & & & \\
CM & & & & \\
Kps & $<0.001$ & $<0.001$ & & \\
Loyal & $<0.001$ & 0.014 & 0.007 & \\
\hline
\end{tabular}

Sumber: Data Primer yang diolah, 2018

Tabel 4. Indirect Effects for Paths With 2 Segments and $P$ Values

\begin{tabular}{lllll}
\hline & \multicolumn{1}{c}{ KP } & \multicolumn{1}{c}{ CM } & Kps & Loyal \\
\hline KP & & & & \\
$\mathrm{CM}$ & & & & \\
Kps & & & & \\
Loyal & 0.070 & 0.118 & & \\
& $\mathrm{p}=0.159$ & $\mathrm{p}=0.044$ & & \\
\hline
\end{tabular}

Sumber: Data Primer yang diolah, 2018

Pengujian Mediasi SEM-PLS dengan metode Variance Acconted For (VAF) ditunjukkan pada Tabel 5. Tahap kedua dalam penelitian ini menunjukkan bahwa pengaruh tidak langsung dalam model terbukti berpengaruh positif dan signifikan pada variabel Citra Merek namun tidak signifikan pada variabel Kualitas Produk.

Tabel 5. Perhitungan VAF

\begin{tabular}{|c|c|}
\hline \multicolumn{2}{|l|}{ Pengaruh Tidak Langsung } \\
\hline $\begin{array}{ll}\text { 1. } & \text { Kualitas } \\
\text { Produk } \rightarrow \text { Kepuasan } \rightarrow \text { Loyalitas }\end{array}$ & 0.070 \\
\hline $\begin{array}{ll}\text { 2. } & \text { Citra } \\
& \text { Merek } \rightarrow \text { Kepuasan } \rightarrow \text { Loyalitas }\end{array}$ & 0.118 \\
\hline \multicolumn{2}{|l|}{ Pengaruh Langsung } \\
\hline 1. Kualitas Produk $\rightarrow$ Kepuasan & 0.300 \\
\hline 2. Citra Merek $\rightarrow$ Kepuasan & 0.509 \\
\hline 3. Kualitas Produk $\rightarrow$ Loyalitas & 0.379 \\
\hline 4. Citra Merek $\rightarrow$ Loyalitas & 0.210 \\
\hline 5. Kepuasan $\rightarrow$ Loyalitas & 0.233 \\
\hline \multicolumn{2}{|l|}{ Pengaruh Total } \\
\hline $\begin{array}{l}\text { Kualitas Produk, Kepuasan dan } \\
\text { Loyalitas. }(0.070+0.379)\end{array}$ & 0.449 \\
\hline $\begin{array}{l}\text { Citra Merek, Kepuasan dan } \\
\text { Loyalitas. }(0.118+0.210)\end{array}$ & 0.328 \\
\hline \multicolumn{2}{|l|}{$\begin{array}{l}\text { VAF = Pengaruh Tidak Langsung/ } \\
\text { Pengaruh Total }\end{array}$} \\
\hline $\begin{array}{l}\text { VAF }=\text { Kualitas Produk }( \\
0.070 / 0.449)\end{array}$ & 0.156 \\
\hline $\begin{array}{l}\text { 2AF }=\text { Citra Merek } \\
(0.118 / 0.328)\end{array}$ & 0.360 \\
\hline
\end{tabular}

Pengaruh tidak langsung antara variabel Kualitas Produk terhadap Loyalitas melalui Kepuasan sebagai variabel mediasi terbukti berpengaruh namun tidak signifikan. Sedangkan pengaruh tidak langsung antara variabel Citra Merek terhadap Loyalitas melalui Kepuasan terbukti berpengaruh dan signifikan.

\section{Kesimpulan dan Saran}

Berdasarkan hasil penelitian yang diperoleh dan dibahas pada bab sebelumnya, maka dapat dihasilkan kesimpulan yaitu: (1) Hasil uji pengaruh langsung pada model penelitian ini menunjukkan hasil pengaruh, yaitu: Adanya pengaruh variabel Kualitas Produk terhadap Kepuasan sebesar 0.300 dengan signifikasi nilai $\mathrm{p}<0.001$; Adanya pengaruh Citra Merek terhadap Kepuasan sebesar 0.509 dengan signifikasi nilai $\mathrm{p}<0.001$; Adanya pengaruh Kualitas Produk 
terhadap Loyalitas sebesar 0.379 dan signifikan dengan nilai $\mathrm{p}<0.001$; Adanya pengaruh Citra Merek terhadap Loyalitas sebesar 0.210 dan signifikan dengan nilai $\mathrm{p}=0.014$; Adanya pengaruh Kepuasan terhadap Loyalitas sebesar 0.233 dan signifikan dengan nilai $\mathrm{p}=0.007$; (2) Hasil uji pengaruh tidak langsung pada model juga menunjukkan hasil pengaruh positif dan signifikan, yaitu: Adanya pengaruh Kualitas Produk terhadap Loyalitas melalui Kepuasan sebesar 0.070 dan dengan nilai $\mathrm{p}=0.159$; Adanya pengaruh Citra Merek terhadap Loyalitas melalui Kepuasan sebesar 0.118 dan signifikan dengan $\mathrm{p}=0.044$; (3) Pengaruh Kepuasan sebagai variabel mediasi dalam model adalah Mediasi Parsial; (4) Hasil perhitungan VAF secara parsial yaitu VAF untuk variabel Kualitas Produk sebesar 0.156 (hampir tidak ada mediasi) dan VAF untuk Citra Merek sebesar 0.360 (parsial mediation); (5) Hasil uji model indicates menunjukkan bahwa model penelitian dapat diterima karena memenuhi godness of fit. Hal ini membuktikan bahwa model penelitian yang menghasilkan uji pengaruh Kualitas Produk dan Citra Merek terhadap Loyalitas melalui Kepuasan sebagai variabel intervening telah sesuai dengan data di lapangan dan hasil uji model ini dapat dijadikan dasar pengambilan keputusan karena sudah bebas dari multikolinearitas.

Berdasarkan hasil penelitian dan kesimpulan yang diperoleh, maka penulis memberikan beberapa saran yang dapat dijadikan masukan sebagai bahan pertimbangan bagi PT. Indosat khususnya IM3, untuk meningkatkan beberapa aspek, yaitu hendaknya PT. Indosat khususnya IM3 diharapkan melakukan perbaikan dan peningkatan terkait Keunggulan Produk dibandingkan dengan pesaing. Karena keunggulan tersebut dapat menjadi nilai tambah bagi suatu produk.

Hendaknya PT. Indosat khususnya IM3 diharapkan melakukan perbaikan dan peningkatan terkait perluasan jangkauan signal. Dengan jangkauan signal yang luas maka akan menjangkau lebih banyak konsumen yang berada di daerah yang jauh dari pusat kota.
Hendaknya PT. Indosat khususnya IM3 diharapkan melakukan perbaikan dan peningkatan terkait kemudahan untuk pengguna kartu IM3 agar meningkatkan kenyamanan dalam menggunakan kartu tersebut.

PT. Indosat khususnya IM3 diharapkan melakukan perbaikan dan peningkatan semaksimal mungkin pada poin - poin yang telah disebutkan dan poin - poin yang belum penulis sebutkan. Karena, persaingan dalam dunia bisnis yang modern ini haruslah dituntut untuk selalu berubah dan berkembang seiring dengan perkembangan zaman.

\section{Daftar Referensi}

Terence, A. Shimp. (2003). Periklanan Promosi. Jakarta: Erlangga

Akbar, Adam. (2012). Analisis Pengaruh Citra Merek, Harga, dan Kualitas Produk Terhadap Keputusan Pembelian Notebook Toshiba. Jurusan Manajemen, Fakultas Ekonomi, Universitas Gunadarma.

Amstrong, Gary \& Philip Kotler. (2002). Dasar-dasar Pemasaran. Jilid 1, Alih Bahasa Alexander Sindoro dan Benyamin Molan. Jakarta: Penerbit Prenhalindo.

Dwi Ratmono \& Mahfud Sholihin. (2013). Analisis SEM-PLS dengan WarpPLS 3.0 untuk Hubungan Nonlinier dalam Penelitian Sosial dan Bisnis. Yogyakarta: Andi Offset.

Freddy Rangkuti. (2002). The Power of Brand, Teknik Mengelola Brand Equity dan Strategi Pengembangan Merek. Jakarta: Gramedia Pustaka.

Ghozali, Imam. (2006). Structural Equation Modelling: Metode Alternatif dengan Partial Least Square. Semarang: Badan Penerbit Universitas Diponegoro.

Heriyati, Pantri. (2012). Analisis Pengaruh Brand Image dan Kualitas Produk Terhadap Keputusan Pembelian 
Konsumen Pada Handphone Nexian. Jurnal BINUS Business School.

Kotler, P. \& G. Armstrong. (2008). Prinsip Prinsip Pemasaran. Jakarta: Erlangga.

Nuraini, Alfiyah. (2015). Pengaruh Celebrity Endoser Dan Kualitas Produk Terhadap Keputusan Pembelian Melalui Citra Merek Pada Kosmetik Wardah Di Kota Semarang. Management Analysis Journal, Vol. 4 No. 2.

Saladin, Djaslim. (2002). Manajemen Pemasaran. Jakarta: Salemba Empat.

Sari, Fajar A. (2015). Pengaruh Harga, Kualitas Produk dan Promosi Terhadap Keputusan Pembelian Lemari Es Merek
LG di PT. Global Elektronik Banyumanik Semarang.

Sugiyono. (2004). Metode Penelitian Bisnis. Bandung: Alfabeta.

Swastha, Basu. (2002). Manajemen Pemasaran. Edisi Kedua. Cetakan Kedelapan. Jakarta: Penerbit Liberty.

T. A, Hidayati. 2013. Pengaruh Citra Merek Terhadap Minat Beli dan Keputusan Pembelian Konsumen Mie Instan Mereka Indomie. Jurnal Fakultas Ilmu Administrasi, Universitas Brawijaya.

Tjiptono, Fandy. 2006. Strategi Pemasaran, Edisi Kedua. Yogyakarta: Penerbit Andi. 